\title{
Case studies - Research and technological solutions to prevent sand production in the gas wells from the Getic Depression
}

\author{
Diana-Andreea Lupu $^{1, *}$ \\ ${ }^{1}$ Lucian Blaga University of Sibiu, Faculty of Engineering, Department of Industrial Engineering and \\ Management, Sibiu, Str. Emil Cioran nr.4.
}

\begin{abstract}
A frequent challenge encountered in the exploitation of mature gas fields located in the Getic Depression is sand production. Causes of sand production are mainly related to degree of rock consolidation, lithology, increasing water production and production rates. The effects of sand production are multiple such us low productivity of the gas wells, accumulation into the surface equipment, erosion of downhole and surface equipment, plugging the perforation zone and casing damage. The current paper will address the sand production- challenges and new perspectives in remedial work of wells which are producing from gas reservoirs located in Getic Depression. The article presents through some case studies the research performed for the implementation of the frac-pack technology in some gas wells.
\end{abstract}

\section{Introduction}

The difficulties encountered in the exploitation of natural gas fields from the Getic depression (Romania) are mainly related to the sand production and the near-reservoir aquifer's expansion. In the current context in which mature gas fields are highly important sources of energy, the problems caused by sand production and finding the optimum technique and technology to prevent or to mitigate them, is a topic of interest for research.

The paper presents in chapter 2 and 3 an original case study related to the research conducted in to a gas field from Romania from Gettic Depression where the technology of frac-pack has been analysed in order to be tested as a pilot technology. The aim of the study is to highlight that the new technology can drive the business performance. Chapter 2 illustrates the steps performed in order to identify the frac-pack technology as a new solution to prevent the sand control while chapter 3 presents the analysis that was conducted to determine the productive potential of the well, respectively the economic analysis which show which is the most profitable solution, as the analysis was done in two scenarios -conventional and through frac-pack.

\subsection{The main causes of sand production}

\footnotetext{
*Corresponding author: diana.lupu@ulbsibiu.ro
} 
Commercial hydrocarbon fields (e.g natural gas) whose permeable porous media would consist of unconsolidated rocks could be included, some of them, in the category of reservoirs whose production of fluids (gas, condensate, water) is also associated with the sand production.

In the practice of gas exploitation from such more or less consolidated formations it has found that for some wells the sand inflow, in small quantities, such $50 \mathrm{~g}$ of sand to 1000 $\mathrm{m} 3$ of gas (personal observation on the well site) [6], does not influence the productive parameters of the wells. On the other hand, a consistent inflow of sand implies, technologically speaking, the establishment on engineering criteria of an optimal flow or operation regime of fluids from reservoir into the well.

The causes of sand influx can be determined by a number of factors, factors that must describe both the nature of the rock formation material and the forces that destabilize the structure of the productive formation. Among the factors that determine the appearance of sand production in the wells, the following are the most important [1]:

a. The degree of consolidation of the reservoir

b. Depletion of the reservoir due to fluid production

c. The well operation regime

d. Multiphase flow

e. Increase in the volume of water produced by the reservoir due to the water drive mechanism.

a. The degree of rock consolidation of the rock is given by the nature of the reservoir rock formation material. In general, reservoir rocks consist of consolidated (sandstone, conglomerate) and unconsolidated (sand), limestone and dolomite rocks. Unconsolidated or poorly consolidated rocks are formed by uncemented mineral grains, and sandstones were formed by cementing sand (the cement can be siliceous, clayey or calcareous nature).

The degree of consolidation increases with the geological age of the formation so that, for example, the reservoir formed in the Mesozoic era are formed by consolidated sedimentary rocks, while the hydrocarbon-bearing formations formed in the Cenozoic era (Sarmatian, Meotian, Pontian, Dacian) are prone to sand production.

$b$. The depletion of the reservoirs a result of the production of fluids and hence the intensification of the sand inflow in the wells is susceptible to further investigations. The decrease of the reservoir pressure, implicitly the decrease of the gas phase density, allows the detachment of very fine sand particles from the rock matrix configuration and their entrainment towards the well.

c. The operating regime of the well is a decisive one in terms of the control of sand production.

The flow of fluids from reservoir into the well is performed based on the differential pressure, which in extreme situations can reach critical values, thus sand inflow. Dislocation of fine sand particles from the matrix of the porous-permeable medium is associated, among others, with the coefficients of total compressibility of the rock.

$d$, e. The multiphase flow and the increase in the volume of water produced by the reservoir due to the water drive mechanism, are the factors that indisputably influence the exploitation performance of these deposits.

The multiphase flow induces the appearance of sand in the well because in the layer during fluid production there is a change in water saturation that increases to a point where the fine particles in the formation begin to be entrained by the liquid phase thus generating local blockages [1].

At the same time, there is an increase in the reservoir-well pressure drop as a consequence of the reduction of the relative permeability, respectively of the blockage given by the migration of fine particles in the near-wellbore. The aforementioned blockage has repercussions on the skin factor in the sense that its value increases significantly. 


\subsection{Difficulties generated in natural gas wells by the appearance of sand production}

The effects of the consistent influx of sand are always generating technological problems, the partial or total solution of which depends on the economic exploitation. The main difficulties which are generated by the sand production that affects the production system, are related to:

Reduced productivity of natural gas wells. Blockages in the pores of the reservoir rock lead to a reduced productivity of the wells and stopping their production. There are also associated issues such as the impossibility of cleaning the perforations in order to re-equip the wells and put them back into production. Although it is a unanimously accepted practice in the industry, namely that of restrictive production, it leads to obtaining small gas recovery factors $(<40-50 \%)$.

Degradation / structural modification of the area behind the exploitation casing. Fluids produced from the reservoir can cause significant volumes of sand, and if production flows are high enough for sufficient periods of time, fairly large caverns can form behind the exploitation casing. Under these conditions, in the absence of a support, there is a collapse of the upper layers in the formed cave. In this situation, next to the perforated casing there is a rearrangement of the environment changing the permeability, in the sense of its drastic decrease, due to the presence of uneven sequences of marl-sand type.

Erosion and corrosion of extraction pipes (tubing). During the workover operations and tubing's evaluation, pieces of tubing were found that had cracks (pitting), eroded gaskets with non-uniformity of material and rust.
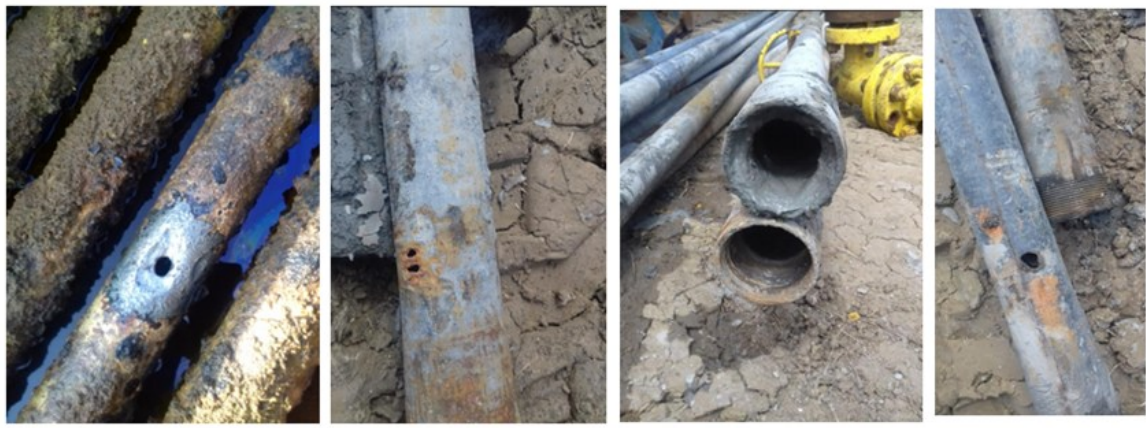

Fig. 1. Pieces of tubing extracted from a natural gas well from Gettic depression during the workover operation

Erosion of the inner seals of the packers. Packers are equipment whose role is to protect the operating casing by isolating it from the tubing. During the operation of the unconsolidated formations, the entrainment of the sand inflow in the well led to the leakage of the inner seals of the packers due to erosion.

Plugging of technological equipment and installations. Although the exploitation of wells prone to sand production is restrictive, the flow rates of fluids are difficult to control, and the multiphase flow induces at some point an influx of sand into wells which causes inconvenience to surface technological installations.

\subsection{Sand production management}

Sand production management is a concept that has developed over the years from traditional methods of restrictive well exploitation, and subsequently, as new technologies for preventing and combating sand inflow have emerged, this concept has gained another meaning. 
The equipment systems for combating sand production were mostly tested in the oil and gas areas of Romania, obtaining remarkable results from the point of view of economic flows. Referring here to equipping the wells with the entire range of mechanical filters, equipping them in a gravel-pack system, resin-coated systems, selective perforation etc. Equipping wells with these systems is advantageous both economically and in terms of the low risk rate in terms of operation failure.

In the case of equipping the well in the frac-pack system, the operating costs are higher, the risks of successful operation are also higher, but the gas rates obtained in the medium and long term are even motivating due to the fact that the new area of inflow reservoir well has a another configuration due to the generous values of the petrophysical parameters.

\section{Frac-Pack (FP) system}

The frac-pack operation involves the simultaneous performance of the hydraulic fracturing operation of the formation and the packing in the gravel-pack system [2]. The fracture is made by using a high viscosity fluid that is pumped by applying a higher pressure than the fracture pressure of the rock. The filters are positioned in the well during pumping, and the proppant is pumped into the fractured channel and into the filter-casing space.

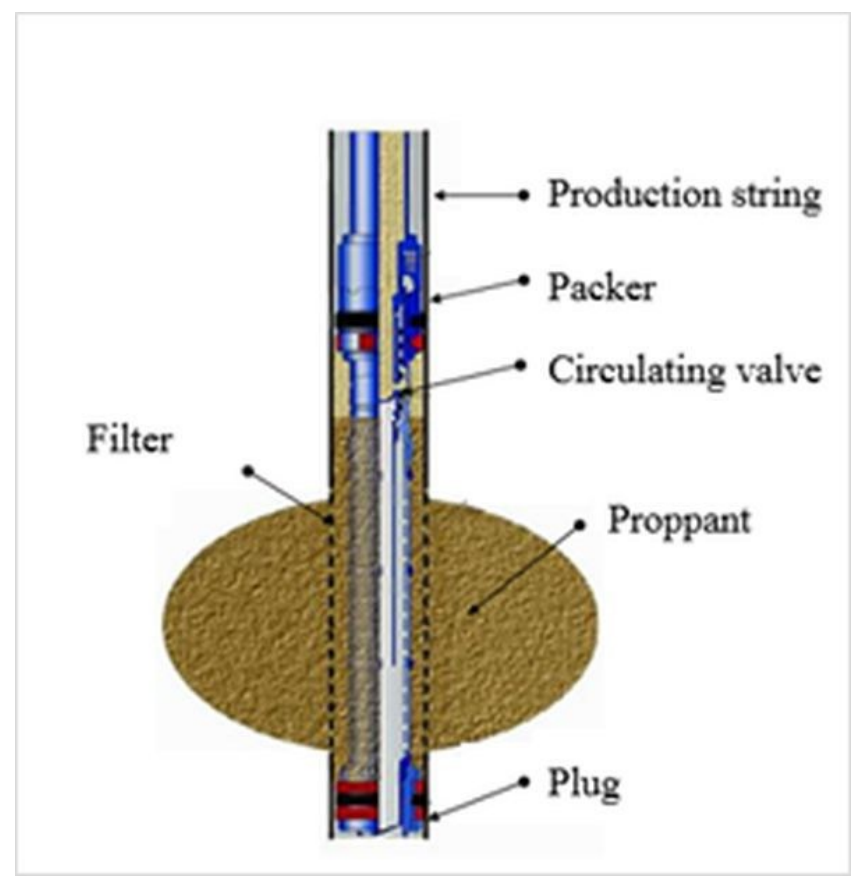

Fig. 2. Frac-pack equipment system [2]

Among the advantages of the frac-pack technique I would list the following:

- Accelerates the production of natural gas by increasing the drainage radius;

- Reconfiguration of the flow geometry of the fluids from layer to well, respectively elimination of the high pressure drop;

- Puts into communication thin layers saturated with gases in interbedded sands-shale formations;

- Stimulates formations with low permeability;

- Reduces potential problems related to the migration of fine particles from the layer by minimizing the pressure drop; 


\section{Research methodology on implementing the frac-pack technology in gas wells from Getic depression}

The natural gas deposits from the Getic depression are characterized from a stratigraphic and lithological point of view from intercalations of marly-sandy rocks, marly sandstones and with calcareous intercalations in Sarmatian, Meotian and Pontian geological ages. The production process from the Meotian age reservoirs is a complex one because the production of fluids is associated with a significant volume of solid particles.

In a research conducted on a natural gas field in the Getic depression that aimed to identify and remedy the difficulties encountered in the exploitation of wells, following the reprocessing of details and information in the history of production, it has been observed and analysed the main factors responsible for sand production, namely:

- Increased water production caused by the advancement of the aquifer adjacent to the hydrodynamic unit. It has noticed that sand production begins to be significant when the volume of water entrained in the well begins to increase as the adjacent aquifer advances. Against the background of the advancement of the aquifer, in the productive layer there is a change in the relative permeability of the gas in the sense that it gradually decreases, and this phenomenon leads to a decrease in the volume of gas recoverable from the formation. By increasing the volume of water and increasing the relative permeability of water to the rock, a high differential pressure is created in the near-wellbore area, and therefore some of the rock grains detach in the form of fine particles and are entrained in well.

The multi-phase (gas-water) flow causes the movement of a very fine clay, because the water saturation increases to a critical point where the fine particles in the marly complex begin to be entrained by the liquid phase (reservoir water), and migrations can create blockages in the pores of the collecting rock. When a multi-phase flow occurs, there is an additional increase in the pressure drop as a consequence of the reduction of permeability, respectively the creation of the blockage generated by the migration of fine particles.

- Depletion of the reservoir. The decrease of the reservoir pressure, implicitly the decrease of the gas phase density, allows the detachment of very fine sand particles from the environment configuration and their entrainment towards the well. The displacement mechanism on the field is a mixed one, namely the gas expansion and the expansion of the adjacent aquifer, where the aquifer proving to be not very aggressive.

The sand control methods used over the years on the analysed structure consisted of:

- Restrictive production method on ranges of chokes with small diameters, between 3 and $5 \mathrm{~mm}$

- Mechanical method (gravel-pack and pre-packaged mechanical filters)

Regarding the mechanical method, at the level of the productive structure in the last 28 years, the situation of the techniques for equipping the wells for sand control is shown in fig. 3:

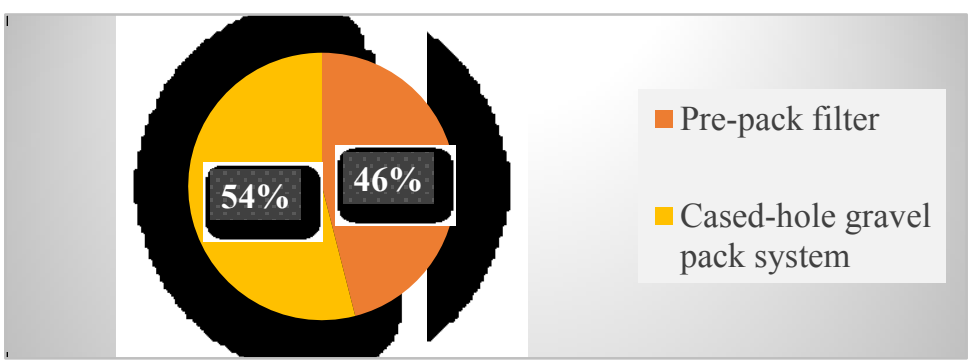

Fig. 3. Sand control systems used between 1990-2018 in the field under research 
The choice of the sand control system was based on particle size analysis, and the selection criterion was Saucier (D50) [4]. Sieve analysis were performed on mechanical cores recovered from 14 wells at different intervals during drilling. The analysis on the operational performance of wells equipped with pre-packaged filter and gravel-pack in the period 1990-2018 showed that 31\% of the wells did not perform in operation because the equipment systems were prematurely plugged with sand during production.

The $31 \%$ percentage, quite high, was an argument for starting a research program in order to identify a new approach from the perspective of equipping the wells to prevent sand inflows and thus increase their productivity.

The steps performed in the research program were as follows:

- Quantitative and qualitative checking of the existing information in the database. Based on the data related to the particle size analysis for each sample, the following statistical parameters were determined:

- D50, according to the Saucier criterion,

- D40 / D90, Uc, uniformity coefficient,

- D10 / D95, Sc, sorting coefficient,

The purpose of this analysis was to determine the appropriate technology for each operating objective so that future well equipment interventions take into account the new criteria for selecting the sand control system [3].
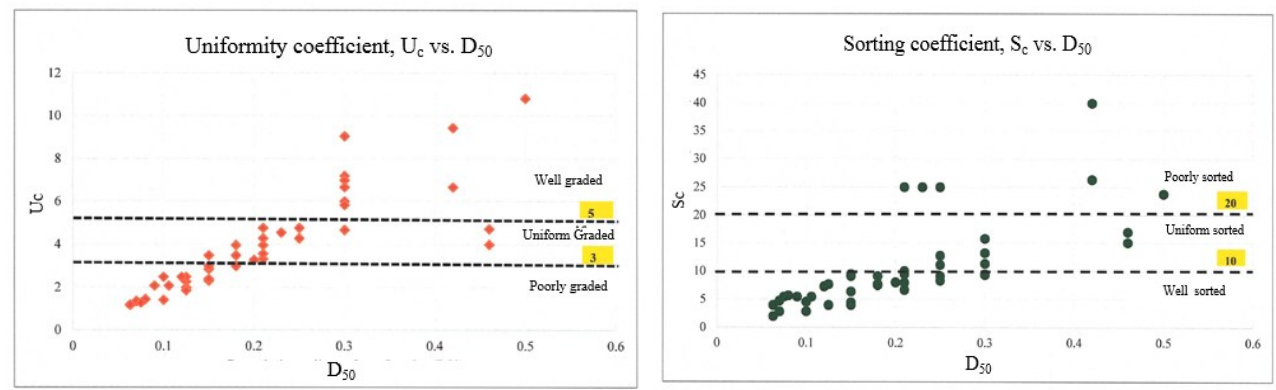

Fig. 4. Uniformity coefficient and sorting coefficient vs D50

The resulted values of the coefficients Uc and Sc compared to the values presented support the use of gravel-pack systems on the field under research, respectively of the prepacked filters, but the presence of fine particles that prematurely block the filters and packing must be taken into account.

- Sampling solid fills from the wells. It has been observed that the appearance of water in the well, known as "water breakthrough", causes sandy particles with marly appearance in the productive layer, and after the discharge of fluids accumulated in the underground separator, and then to the measurement tank, the water (which looked dirty) at the bottom of the hatch remained a consistent deposit of fine particles.

It has recovered samples from 6 wells ( 5 wells operated the Meotian formation, and one well exploited the Sarmatian formation) and the following laboratory analyses were performed:

- Solubilization in $\mathrm{HCl}$ acid (15\%) and $\mathrm{HCOOH}$ acid (15\%).

- Particle size analysis (determination of average particle diameter, d50)

The solubilization test of the deposition in acid solutions aimed to confirm whether or not the deposits are in the category of "fine particles" [5]. The analysis showed that the degree of solubilization of solid particles is very small, between $4-10 \%$, they do not dissolve in the acid solution, confirming that they are very fine particles. The grain size analysis showed that the average particle diameter, $\mathrm{d} 50$, is between $0.09-0.140 \mathrm{~mm}$. 
- Identifying a new technical approach to equipping wells in order to optimize production.

In order to improve the productive performance of the wells and to design the continuation of the exploitation of the gas field under research, it has been analysed the opportunity to carry out an experimental research (pilot test) for the application of frac-pack technology on the natural gas structure in the Getic depression.

The considerations for which it was admitted that this technology is opportune to be tested on gas field under research are the following:

- Existence of marly complexes with sand intercalations at the Meotian IV a and Meotian IV $b$ exploitation objectives. By conventional perforation there is the possibility that certain intercalations to be by-passed and not put in communication with the well;

- Following the analysis of the standard electrical logs of the wells, it was found that it is not possible to highlight, in the sense of separation, the intercalations saturated with gases in the marly complexes;

- The classic equipment operation in the gravel-pack system induces a positive mechanical blockage (skin), whose value is relatively high (usually $S=+50$ ), compared to the frac-pack technique, which practically eliminates this inconvenience;

- From an economic point of view, frac-pack equipment is much more cost-effective compared to conventional equipment due to reduced operating costs.

Starting from these premises, it has been analysed all the existing gas wells on the structure taken in the case study and it has been made a list of candidate wells for the fracpack pilot test.

The preliminary selection criteria for the candidate wells were as follows:

- Optimal positioning of the well from a structural point of view (on the apex) with the consequence of reducing the risk of accessing areas possibly affected by the advance of aquifers;

- Integrity of the operating casing, good cement behind casing. In order to validate these aspects, it was analysed if the MIT-Multifinger Investigation Tool, RBL-Radial Bond Log, acoustic cementation logging investigations already were run, and if they are missing it is necessary to perform the investigations listed above ;

- The selection of the wells was conditioned by the favourable results obtained by the neighbouring wells that exploited the formations Me IV a and Me IV b, marly formations with sand intercalations hardly observable on the electric standard log.

A solution to this situation would be to carry out logs to determine the saturation in fluids in the areas where the equipment in the frac-pack system is intended.

The above criteria materialized in the selection of three wells for the pilot test, wells called, generically, well \#1, well \#2, well\# 3 .

\section{Productive and economic performance simulation to implement the pilot project in the selected wells}

\subsection{Technical analysis}

To determine the productive potential, a simulation (nodal analysis) was performed taking as reference a probe that exploited the Meotian IV b objective (candidate objective for production in the frac-pack system). The working methodology was similar for all wells, but in the present paper the analysis is presented only for one well (well \# 3).

The input parameters for nodal analysis were as follows:

- Current average field pressure: 112 bar, 
- Productivity index calculated using the dynamic pressure data measured in the reference well: $2,35 \mathrm{kscm} / \mathrm{bar}^{2}$,

- The value of the skin factor determined from the interpretation of the pressure build up well test, in the reference well: $\mathrm{S}=3$.

- Choke size: $\mathrm{d}=3.5 \mathrm{~mm}$.

Following the nodal analysis and the sensitivity analysis (modification of the diameter of the choke size) the data resulted is presented in table 1 .

Table 1. The results of the nodal analysis and the sensitivity analysis regarding the operation of well \# 3 in the conventional system vs. frac-pack system (comparative analysis)

\begin{tabular}{|c|c|c|c|}
\hline $\begin{array}{c}\text { Resulted parameters from } \\
\text { nodal analysis }\end{array}$ & $\begin{array}{c}\text { Conventional exploitation } \\
\text { of well \#3 }\end{array}$ & \multicolumn{2}{|c|}{ Frac-pack exploitation of well \#3 } \\
\hline P90 & 9,5 & P50 & P10 \\
\hline Initial gas rate [kscm/d] & 3 & 28 & 36 \\
\hline Skin factor & 3,5 & -4 & -4 \\
\hline Choke size [mm] & 15 years & 6 & 8 \\
\hline Production period & \multicolumn{2}{|c|}{6 years } \\
\hline
\end{tabular}

As can be seen in Table 1, three scenarios for the continuation of the operation of well \# 3 were considered, respectively three probability scenarios, namely:

- Conventional operating scenario, basic scenario (P90) in which well \# 3 will be operated on a choke size of $3.5 \mathrm{~mm}$, around the well there will be a skin factor of 3, and the well will go into production at Me IVa package with an estimated gas flow of $9.5 \mathrm{kscm} /$ day. The estimated production is approximately 15 years, resulting from the production forecast made by the production decline method.

- Exploitation scenario in frac-pack system, realistic scenario (P50) in which well \# 3 will be exploited on a choke size of $6 \mathrm{~mm}$, around the well being estimated a negative skin factor of -4 being a stimulated formation, and the well will enter production at the Me IVa package with an estimated gas flow of $28 \mathrm{kscm} /$ day.

- Frac-pack operation scenario, optimistic scenario (P10) in which well \# 3 will be operated on a choke size of $8 \mathrm{~mm}$, the well entering production at the Me IVa package with an estimated initial gas flow of $36 \mathrm{kscm} /$ day.

For the last two scenarios, the exploitation period is 6 years, as a result of the intensification of the production and the recovery of the natural gas reserves in a much shorter time.

In fig. 5 are presented graphically, the results of the nodal analysis for well \# 3, respectively the IPR performance curves related to each exploitation scenario described above. The vertical axis (112 bar) and the estimated pressure in the field (35 bar) are represented on the vertical axis. The natural gas rates are expressed on the horizontal axis, as a result of calibrating the gas flow simulation in the production system using Darcy's equation. The intersection of the reservoir performance curves with the performance scenarios of the exploitation scenarios will render the natural gas flows estimated to be produced.

Figure 6 illustrates the production forecast in the two scenarios, scenarios that correspond to the notations in the legend. The methodology used was production decline. As can be seen, in the case of well \# 3, the recovery of reserves by the frac-pack method can be achieved in a much shorter period of time compared to the conventional method. 


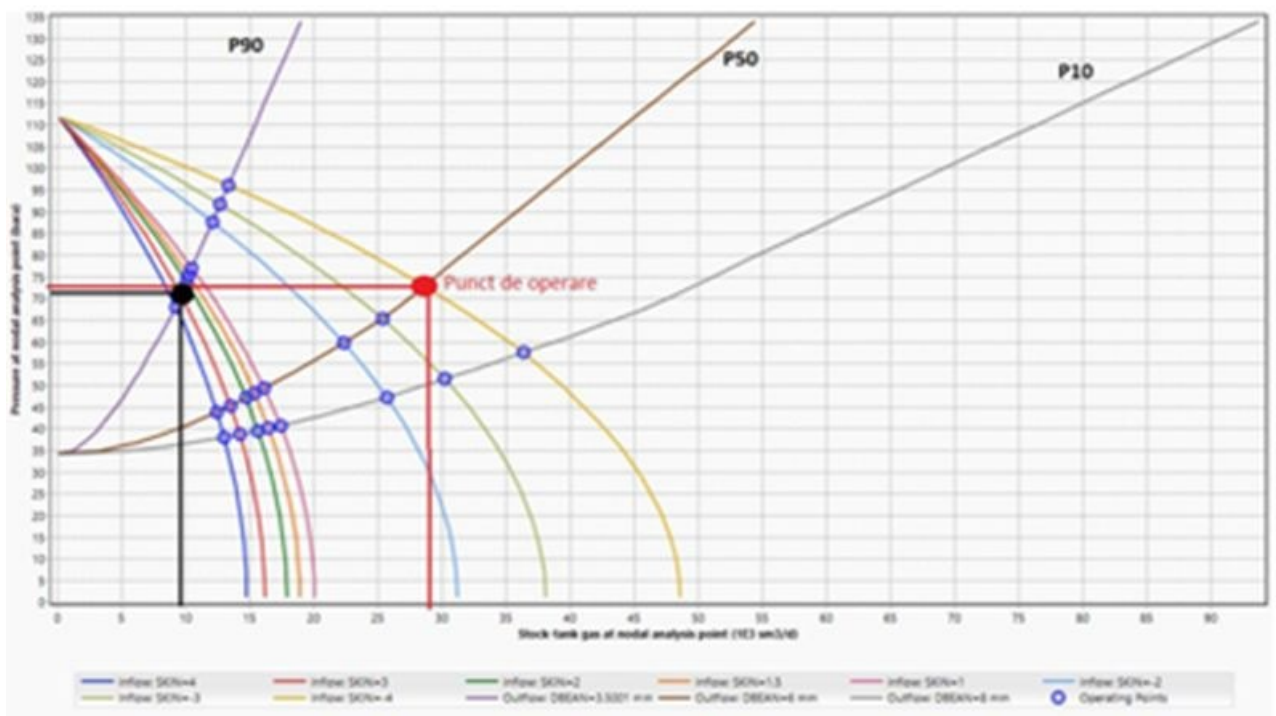

Fig. 5. The results of the nodal analysis presented comparatively: exploitation in conventional system vs. frac-pack operation (well \# 3)
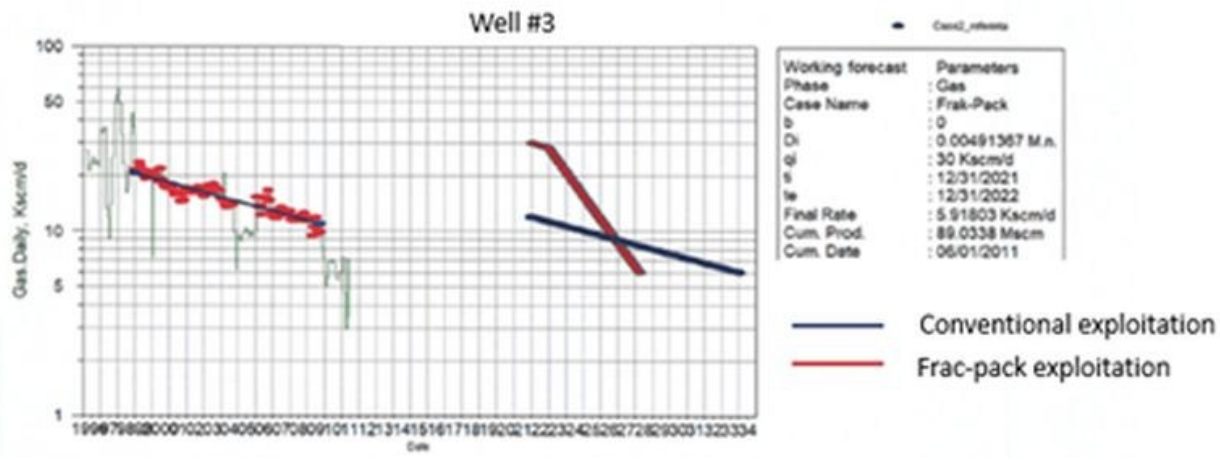

Fig. 6. Production forecast for well\#3

\subsection{Economic analysis}

The economic results for well \# 3 to be put into operation for the Me IV objective are illustrated in Table 2. The investments related to the two exploitation scenarios are of 160 thousand USD in conventional system, respectively 465 thousand USD in frac-pack system for the recovery of an estimated volume of $36 \mathrm{Mcm}$. In the scenario of operation in conventional system the economic limit year is 2033 with an estimated NPV at a discount rate of $10 \%$ of 1585 thousand USD, and in the scenario of operation in frac-pack system the economic limit year is 2028 with an estimated NPV of 2080 thousand USD. Thus, between the two variants of continuing the operation, the optimal scenario is the one in the frac-pack system, from which an additional 495 thousand USD is obtained. 
Table 2. Estimated value of investment

\begin{tabular}{|c|c|c|c|c|}
\hline Scenario & $\begin{array}{c}\text { Estimated value } \\
\text { of investment } \\
\text { (thousands } \\
\text { USD) }\end{array}$ & $\begin{array}{c}\text { Economic limit } \\
\text { year }\end{array}$ & $\begin{array}{c}\text { NPV } \\
\text { (thousands } \\
\text { USD) }\end{array}$ & $\begin{array}{c}\text { Estimated } \\
\text { production } \\
\text { (Mcm) }\end{array}$ \\
\hline Conventional & 160 & 2033 & 1585 & 36 \\
\hline Frac-pack & 465 & 2028 & 2080 & 36 \\
\hline
\end{tabular}

In conclusion, following the results of the technical-economic analysis, it has proposed a pilot test to equip the 3 wells in the frac-pack system on the field under research located in the Getic Depression, the test having as main objective the prevention of premature sanding of the wells, respectively the increase of the recovery factor of the natural gas reserves in optimal conditions of exploitation and profitability.

\section{References}

1. D-A. Lupu, D-P. Ștefănescu, I. Foidaș, AGH Drilling Oil and Gas, 36, 1 (2019).

2. A. Ghalambor, A. Syed, W.D. Norman, Frac Packing Handbook, (Society of Petroleum Engineers, 2009).

3. D.L. Tiffin, G.E. King, R.E. Larese, L.K. Britt, SPE-39437-MS, New Criteria for Gravel and Screen Selection for Sand Control, (Lafayette, Louisiana, USA, 1998).

4. R.J. Saucier, Journal of Petroleum Technology, 26, 02 (1974).

5. M. Bramao, Downhole Remediation of Production Restrictions in Gas Wells, (Schlumberger, Medias, 2018).

6. D-A. Lupu, Contributions regarding the stimulation of the gas inflow in the wells with technological problems, through the rehabilitation of the reservoir-well system, Doctoral Thesis (Petroleum Gas-University of Ploiesti, Ploiesti, Romania, 2021) 